\title{
Apontamentos sobre a práxis de Relações Públicas na web
}

Notes on Public Relations practices on the web

\author{
Apuntes sobre la práxis de las Relaciones \\ Públices en la web
}

Eugenia Mariano da Rocha Barichello

- Doutora em Comunicação pela Universidade Federal do Rio de Janeiro (UFRJ)

- Coordenadora do Programa de Pós-Graduação em Comunicação da Universidade Federal de Santa Maria (UFSM)

- Líder do Grupo de Pesquisa de Comunicação Institucional e Organizacional UFSM/CNPq

- eugeniabarichello@gmail.com

\section{Daiana Stasiak}

- Mestre em Comunicação pela Universidade Federal de Santa Maria (UFSM)

- Professora do Curso de Comunicação Social da Universidade Federal de Goiás (UFG0)

- Membro do Grupo de Pesquisa de Comunicação Institucional e Organizacional UFSM/CNPq

- daiastasiak@gmail.com 
Este trabalho apresenta os resultados de pesquisa que teve como objetivo classificar as diferentes fases da práxis de Relações Públicas na web (WebRP) ao longo dos últimos catorze anos. A metodologia utilizada foi o estudo de casos múltiplos. O corpus foi formado por doze portais analisados em três momentos: anos 1990, início dos anos 2000 e atualidade (2008/2009). Ao final das análises encontramos as estratégias pertinentes a cada época que permitiram a tipificação de três fases da WebRP.

PALAVRAS-CHAVE: RELAÇ̃̃ES PÚBLICAS • ESTRATÉGIAS DE COMUNICAÇÃO • PORTAIS • LEGITIMAÇÃO INSTITUCIONAL・ MIDIATIZAÇÃOO

\section{Abstract}

This work presents research results that had the purpose of classifying different phases of Public Relations practices on the web (WebRP), in the course of the last fourteen years. The methodology uses the multiple cases study, where the core was developed from twelve sites studied at three different moments: the 1990s, the beginning of the 2000 decade and present time $(2008 / 2009)$. At the end of the analyses we found the pertinent strategies for each period, which enabled categorization of the three WebRP phases.

KEYWORDS: PUBLIC RELATIONS • COMMUNICATION STRATEGIES • SITES • INSTITUTIONAL LEGITIMATION • MEDIATIZATION

Resumen

Se presentan los resultados de una investigación que tuvo por objetivo clasificar las diversas fases de la práxis de las Relaciones Públicas en la web (WebRP) en los últimos catorce años. Se utilizó una metodología basada en el estudio de casos múltiples. El corpus está formado por doce sitios analizados en tres momentos: la década de 1990, el inicio de la década de 2000 y el momento actual (2008/2009). Los análisis revelaron las estrategias pertinentes a cada época, que permitieron la tipificación de tres fases de WebRP.

PALABRAS CLAVE: RELACIONES PÚBLICAS • ESTRATEGIAS DE COMUNICACIÓN • SITIOS • LEGITIMACIÓN INSTITUCIONAL・ MEDIATIZACIÓN 
0 termo WebRP significa neste trabalho as práticas de Relações Públicas efetuadas na interface da web e é entendido a com base nas teorias do webjornalismo (MIELNICZUK, 2003; BARBOSA, 2007). Por meio da análise dos portais buscou-se evidenciar e discutir a materialidade de um novo tipo de estratégia de comunicação institucional, que se manifesta nas teias da rede e está presente nas práticas cotidianas da atividade de Relações Públicas.

Kunsch (2003) trata das dimensões da práxis de Relações Públicas e define como natureza da profissão o trabalho com os aspectos institucionais das organizações com base em atividades específicas e no uso de instrumentos e meios que permitem diagnosticar, prognosticar, propor políticas e implementar programas e instrumentos que assegurem a interação com os públicos.

$\mathrm{Na}$ atualidade, os portais disponibilizados na internet são um dos principais expoentes de interação com os públicos, mas esses dispositivos sociotécnicos não são utilizados e nem estudados em todo o seu potencial. Essas novas possibilidades para concretizar práticas de Relações Públicas podem gerar consequências como a prevalência de relacionamentos virtuais com os públicos melhor seria denominá-los interagentes - por meio de portais, blogs, comunidades virtuais, chats e fotologs.

\section{Estudo de casos múltiplos}

Utilizou-se como metodologia o estudo de casos múltiplos com base em Yin (2005), caracterizado por uma pesquisa que envolve duas ou mais pessoas ou organizações, em uma lógica de replicação e não de amostragem, com o que os critérios típicos adotados em relação ao tamanho da amostra se tornam irrelevantes.

O corpus da pesquisa foi construído em duas etapas. Na primeira selecionaramse dois portais de cada um dos 25 domínios registrados para pessoas jurídicas no órgão Registro. Br, responsável por manter e distribuir todos os endereços de portais disponíveis no Brasil. Os domínios foram digitados em ferramentas de busca da internet e a seleção de dois portais por domínio levou a um total de cinquenta portais.

A segunda etapa considerou os catorze anos de uso da internet no Brasil, tendo-se estabelecido que os portais selecionados para o estudo de casos múltiplos deveriam estar presentes na rede, em média, há pelo menos nove anos, ou seja, antes do ano 2000. Para que esse critério fosse atendido, utilizou-se uma ferramenta denominada Internet Archive Wayback Machine (IAWM), um serviço que se dedica a recolher e arquivar versões de páginas web e permite que os usuários considerem versões arquivadas das web pages do passado. Os cinquenta portais selecionados inicialmente foram digitados nessa ferramenta, 
tendo apenas oito deles apresentado registros anteriores ao ano 2000. Devido ao pequeno número de casos encontrados, optou-se por adicionar ao corpus de pesquisa o domínio Com.br, que se caracteriza como um domínio genérico utilizado para registrar portais tanto para pessoas físicas quanto para pessoas jurídicas. Pelo mesmo processo se selecionaram mais quatro portais que se enquadraram no protocolo de estudos pré-estabelecido.

Concluídas as duas etapas, chegou-se a um total de doze portais, que formaram o corpus final de estudo. Os objetivos da pesquisa exigiram a análise dos portais em três momentos: anos 1990 (portais de 1995 a 1999); anos 2000 (portais de 2001 a 2005); e atualidade (portais de 2008 e 2009). A divisão cronológica foi realizada a partir das constatações da análise que evidenciaram características capazes de serem agrupadas nesses três momentos.

\section{As estratégias de comunicação de cada tempo}

Com base na literatura de Relações Públicas e na normatização de órgãos reguladores da profissão, elaborou-se uma lista de 27 estratégias de comunicação consideradas norteadoras dessas práticas e representadas neste estudo pelos links presentes nos portais institucionais. São elas: 1. Apresentação da organização: fundação e história; 2 . Pontos de identidade visual; 3. Missão e visão; 4. Sinalização virtual; 5. Hierarquia organizacional; 6. Normas e regimento organizacional; 7. Agenda de eventos; 8. Publicações institucionais; 9. Acesso em língua estrangeira; 10. Sistema de busca interna de informações; 11. Mapa do portal; 12. Contato, "fale conosco", ouvidoria; 13. Pesquisa e enquete on-line; 14. Presença de notícias institucionais; 15. Projetos institucionais; 16. Visita virtual; 17. Serviços on-line; 18. Clipping virtual; 19. Comunicação dirigida; 20. Espaço para imprensa: releases e galeria de imagens; 21. Uso do hipertexto (texto + som + imagem); 22. Personagens virtuais; 23. Presença de tevê e rádio on-line; 24. Transmissão de eventos ao vivo; 25. Disponibilização de "fale conosco" interativo; 26. Presença de chats; 27. Link de blog organizacional.

No primeiro período (1995-1999), os portais apresentaram em média apenas um terço das 27 estratégias norteadoras do estudo. Entre as estratégias de contato predominavam os telefones e os endereços físicos da organização. A presença de instruções aos usuários e explicações dos modos de acesso às informações foram marcantes. Predominou o uso de figuras e desenhos. A presença de links longos e autoexplicativos e dos ícones "novo" e "new" também foi constante nos portais. A maioria apresentou contadores de acesso.

No segundo período (2001-2005), as estratégias de publicações institucionais estavam em quase todos os portais e iniciou-se o uso de comunicação dirigida. Ainda estavam presentes indicadores de contatos telefônicos, mas já apare- 
ceram endereços de e-mails e formulários eletrônicos. As notícias ocupavam local de destaque nas colunas centrais, as estratégias de aproximação com a imprensa foram intensificadas e tiveram início algumas possibilidades interativas entre os públicos como links de fóruns.

No terceiro período (2008-2009) se destacam as estratégias de comunicação dirigida e os espaços multimidiáticos. Predomina a presença de vídeos e a maioria dos portais apresenta algum tipo de imagem móvel, incluindo personagens virtuais. Os sistemas de busca e os serviços on-line são estratégias muito presentes e possibilitam quase todos os tipos de serviço da organização por meio do portal. O blog organizacional, a transmissão de eventos ao vivo e a teleconferência foram estratégias encontradas apenas em portais desse período e parecem indicar a busca por interatividade e a utilização do espaço da web para unir os públicos por meio de eventos virtuais.

\section{Considerações pontuais}

A análise empírica dos portais e a tipificação das estratégias de comunicação na web nos levam a entender o uso do portal como uma adequação das organizações ao bios virtual proposto por Muniz Sodré Cabral (2002). Estamos diante de acontecimentos apresentados em tempo real, característica principal desse novo ambiente que também pode ser considerado como um marco da passagem da comunicação de massa centralizada, vertical e unidirecional para o espaço de possibilidades em rede. Isso conduz à compreensão das práticas de Relações Públicas sob o prisma das novas tecnologias e das formas de representação e sociabilidade nelas imbricadas.

A primeira fase das práticas de WebRP (1995-1999) caracteriza-se pela busca e pelo conhecimento de um novo espaço (portal) e pelo crédito a uma mídia em ascensão (internet) que ainda não tinha seus resultados de visibilidade comprovados. A nova mídia possuía um forte apelo de modernização e transformação dos modos de se disponibilizar informações para os públicos, que não dependia mais exclusivamente das mídias tradicionais. E quebrava, de certo modo, a lógica de emissor-canal-receptor, pois oferecia aos públicos mais possibilidades de interagir diante de um contexto.

A segunda fase (2001-2005) passa a ser de exploração de um espaço que exige conteúdos diferenciados. Em linhas gerais essa constatação resultou em um aumento da oferta de serviços on-line, melhor aproveitamento das seções de notícias e publicações institucionais, maior abertura para as formas de contato virtual com os públicos, estratégias de comunicação dirigida e uso de perguntas em enquetes feitas por meio do portal.

A terceira fase (2008-2009) evidencia a evolução do sistema web e sua presença cada vez maior no cotidiano da vida das pessoas. Nas práticas de Relações Pú- 
blicas isso se reflete em estratégias da internet conectadas às estratégias para as demais mídias, contato mais dirigido a cada público e aproveitamento das possibilidades do uso de estratégias multimídia.

\section{Referências}

BARBOSA, Suzana. Jornalismo Digital em Base de Dados (JDBD): um paradigma para produtos jornalísticos digitais dinâmicos. Tese (Doutorado em Comunicação) - Faculdade de Comunicação, Universidade Federal da Bahia, Salvador, 2007.

CABRAL, Muniz Sodré de Araújo. Antropológica do espelho: por uma teoria da comunicação linear e em rede. Petrópolis, RJ: Vozes, 2002.

KUNSCH, Margarida M. Krohling. Planejamento de relações públicas na comunicação integrada. 4. ed. rev., atual. e ampl. São Paulo: Summus, 2003.

MIELNICZUK, Luciana. Jornalismo na web: uma contribuição para o estudo do formato da notícia na escrita hipertextual. Tese (Doutorado em Comunicação) - Faculdade de Comunicação, Universidade Federal da Bahia, Salvador, 2003.

YIN, Robert K. Estudo de caso: planejamento e métodos. Porto Alegre: Bookman, 2005. 